thermo-gravimetric, lysimetric, penetration, chemical, and nuclear methods. The most successful nuclear method uses a probe containing a source of fast neutrons, which are slowed down by the hydrogen of the soil moisture, and a slow neutron detector. The energy of soil moisture may be measured by tensiometric-pressure, vapour-pressure, thermal and electrical methods. The resistance block is cheap and can give values over a wide range, but it is not very precise. Other methods await adequate investigation or improvement, and some system of automatic recording is required to reduce the labour of replication needed because of soil variability.

\section{Archaeology in Tasmania}

ScIENTIFIC archaeological research in Tasmania has only recently been initiated, and one of the first reports of such work appears in Man ("Excavations on a Stone Arrangemont in Tasmania", by Rhys Jones; 65, No. 62, May-July 1965). This is a short interim report of an expedition to the Bay of Fires on the north-east coast of the island, which resulted in the excavation of a shell midden with two stratified stone alignments. The stone arrangements of Australia have for long been known to exist, and these excavations demonstrated that at least some of the arrangements must be of Aboriginal origin. By analogies with certain stone settings of the Australian mainland, it is possible that the Bay of Fires alignments served as ceremonial centres, and the nature of the site shows for the first time that the tradition of such stone arrangements in Tasmania must have existed for an appreciable length of time.

\section{The Antikythera Shipwreck}

THE shipwreck off the island of Antikythera, first discovered in 1900 , is well known not only because it was the first ancient wreck found but also because of the extraordinary range of objects recovered, including the famous computer. Some controversy has developed concerning the date of the wreck, and, using a recent examination of the computer as a basis, a team of specialists has examined in detail the glass vessels, the Greek and early Roman pottery and amphorae, in an attempt to fix more precisely the date of the disaster (The Antikythera Shipwreck Reconsidered. By G. D. Weinberg, V. R. Grace, G. R. Edwards, H. S. Robinson, P. Throckmorton and E. K. Ralph. Pp. 48. Trans. Amer. Phil. Soc., New Series, 55, Part 3, 1965). All the lines of evidence suggest a time between 80 and 50 B.c., although a fragment of wood from the ship yielded a radiocarbon date of $220 \pm 43$ B.c. ( $P-846$, half-life of $5,730)$. This represents the time of the cutting of the timber for planking. The main cargo of the vessel, sculpture, must have been on its way to Rome as spoils from the east Mediterranean shores, although its exact place of origin is still unknown. Fragments of the actual ship were recovered in 1900 , and $P$. Throckmorton contributes a careful assessment of their value towards a reconstruction of the vessel. This has been augmented by the 1953 underwater examination of the wreck by men from the Calypso, which suggests that a substantial part of the vessel must still await recovery from the great depth of $180 \mathrm{ft}$.

\section{Biology and Human Affairs}

Thirty years ago biology was little studied in the schools of Britain. In the junior schools the teaching of biology consisted almost entirely of nature study or natural history; in secondary schools little but botany was taught and that largely in girls' schools. In 1935 the journal Biology was founded by the then British Social Hygiene Council with the general aim of developing the teaching of biology in schools. The particular aim was that children might grow up with a better understanding of the structure and working of their own bodies and acquire a greater sense of responsibility for their conduct in personal and social life. With the spread of biology teaching, the Council broadened its aims to focus greater attention on human biology and, in 1942, the name of the journal was changed to Biology and Human Affairs. From the beginning it has appeared once a term and, largely through voluntary effort, has maintained a high standard of contributions which have done much to bring about greater awareness of social biology among those who teach biology in schools and colleges. For nearly the whole of its existence the editor of the journal has been R. Weatherall, late of Eton College, who must be congratulated on maintaining such a high standard in a wide range of contributions over so many years. Further information about the journal can be obtained from the Editor, British Social Biology Council, 69 Eccleston Square, London, S.W.1.

\section{Experiments on Living Animals}

The Universities Federation for Animal Welfare (UFAW), $7 a$ Lamb's Conduit Passage, London, W.C.1, has issued the following statement: "The Home Office report on the above subject for the past year, which was published on August 17, shows that of the 4.5 million animals affected, 4 million were used for the testing of drugs, for experimental inoculations, and for like purposes. A large proportion of such procedures are concerned with toxicity-testing, which has greatly increased since the thalidomide tragedy was so dramatized as to give rise to a panic. In our view, which seems to be shared by most scjentists who have a knowledge of the subject, many of the tests are necessitated by what may be called 'political' rather than scientific considerations and are, in fact, valueless, entailing a wasteful use of animals; moreover, in other cases it may well become possible to improve the technique from a humane point of view. UFAW is accordingly about to set on foot, under the guidance of its expert Scientific Advisory Committee, a three-year investigation of toxicity-testing, centred in the Medical School in the University of Birmingham and directed by one of the most eminent authorities on the subject. This undertaking will cost at least $£ 30,000$, but while its primary object is to save animals from useless suffering it is almost certain to lead also to results beneficial to human medicine, if the requisite financial support can be obtained".

\section{Field Equipment for Naturalists}

MUCH useful advice for naturalists contemplating the purchase of binoculars, telescopes, tape-recorders, tents, clothing, transport, compasses, thermometers, barometers, light meters, maps or cameras is contained in a special supplement of Animals (6, No. 14). The issue also contains articles on "Marine Life of North America's Pacific Coast", by Prof. C. M. Yonge; "Bird Watching in Jamaica", by M. S. Curtler; "Pets", by Dr. Maurice Burton; "The Ngorongoro Crater", and "Lake Manyara National Park"; and "Britain's Bats", by S. L. Bisserot.

\section{Lincolnshire Naturalists}

IN his presidential address to the Lincolnshire Naturalists' Union, Frank Norris reviewed present knowledge about the snakes of Lincolnshire, and appealed for an extension of the reporting system, with emphasis on observations of behaviour (Transactions of the Lincolnshire Naturalists' Union, 16, No. 1; December 1964). Besides the usual sectional reports, the Transactions also contain articles on the "Basal Lias near Long Bennington", by Dr. P. E. Kent; "Lincolnshire Natural History Recording Units", by Mark R. D. Seaward; and "Biological Surveys of the Humber Estuary", by E. Hinton Clifton.

\section{The Beilby Medal and Prize, 1966}

Awards from the Sir George Beilby Memorial Fund are made by the Administrators of the Fund, representing 